PACS 61.10.-i, 61.72.-y, 61.72.Dd, Nn

\title{
Stacking Faults in the single crystals
}

\author{
Mihir M. Vora ${ }^{1}$ and Aditya M. Vora ${ }^{1,2^{*}}$ \\ ${ }^{1}$ Parmeshwari 165, Vijaynagar Area, Hospital Road, Bhuj-Kutch, 370 001, Gujarat, India \\ ${ }^{2}$ Humanities and Social Science Department, S. T. B. S. College of Diploma Engineering, Opp. Spinning Mill, \\ Varachha Road, Surat 395 006, Gujarat, India \\ *Tel.: +91-2832-256424; e-mail:voraam@yahoo.com
}

\begin{abstract}
The single crystals of $\operatorname{In}_{x} \mathrm{MoSe}_{2}(0 \leq x \leq 1)$ and Re-doped $\mathrm{MoSe}_{2}$ viz. $\mathrm{MoRe}_{0.005} \mathrm{Se}_{1.995}, \mathrm{MoRe}_{0.001} \mathrm{Se}_{1.999}$ and $\mathrm{Mo}_{0.995} \mathrm{Re}_{0.005} \mathrm{Se}_{2}$ have been grown by a direct vapour transport technique (DVT) in the laboratory. Structural characterization of these crystals was made using the XRD method. The particle size for a number of reflections has been calculated using the Scherrer formula. There are considerable variations appearing in deformation $(\alpha)$ and growth $(\beta)$ fault probabilities in $\operatorname{In}_{x} \operatorname{MoSe}_{2}(0 \leq x \leq 1)$ and Re-doped $\mathrm{MoSe}_{2}$ single crystals due to their off-stoichiometry, which possesses the stacking fault in the single crystal.
\end{abstract}

Keywords: $\operatorname{In}_{x} \mathrm{MoSe}_{2}(0 \leq x \leq 1)$ single crystals, Re-doped $\mathrm{MoSe}_{2}$ viz. MoRe ${ }_{0.005} \mathrm{Se}_{1.995}$, $\mathrm{MoRe}_{0.001} \mathrm{Se}_{1.999}$ and $\mathrm{Mo}_{0.995} \mathrm{Re}_{0.005} \mathrm{Se}_{2}, \mathrm{XRD}$, particle size, deformation probability, growth probability, stacking fault.

Manuscript received 14.07.09; accepted for publication 10.09.09; published online 30.11.09.

\section{Introduction}

Perfect crystals are not available in nature or fabricated in laboratory, it is an ideal concept. There are several types of defects that are present in crystal, namely: point defects, stacking faults etc. The study of stacking faults is made either by using electron microscope or the X-ray diffraction method $[1,2]$. In recent years, transition metal dichalcogenides of the groups IV-b, V-b and VI-b have obtained considerable attention because of their uses particularly as electrodes in photoelectrochemical solar ce1ls for conversion of solar energy into electrical energy as well as photonic devices in various electronic applications. These compounds crystallize in a quasi-twodimensional layer structure consisting of chalcogenes held together by the relatively weak Van der Waals forces. Because of these weak Van der Waals forces between the layers, one can observe intercalation of foreign atoms, ions or neutral molecules to form new compounds. Intercalated compounds of disulphide and diselenide of molybdenum and tungsten have been extensively studied by various researchers. These crystals become superconducting when being intercalated with alkali and alkaline earth metals [1-10]. The study of stacking faults is very important, because it plays an important role in description of the defects. The conversion behaviour of a solar cell is closely related to the perfection of the electrode material, and since stacking faults play a fundamental role in the description of defects structure, their study is of both practical and theoretical interest [2].
The enhanced conduction caused by the stacking faults along the c-axis is difficult to understand because of the extreme two-dimensional character of the layered compounds of $\mathrm{MoSe}_{2}$ and its intercalated compounds $\mathrm{In}_{\mathrm{x}} \mathrm{MoSe}_{2}(0 \leq x \leq 1)$ and Re-doped $\mathrm{MoSe}_{2}$ compounds viz. $\mathrm{MoRe}_{0.005} \mathrm{Se}_{1.995}, \quad \mathrm{MoRe}_{0.001} \mathrm{Se}_{1.999}$ and $\mathrm{Mo}_{0.995} \mathrm{Re}_{0.005} \mathrm{Se}_{2}$. The only way to understand this conduction is by supposing the presence of stacking faults in these crystals. It is clear from the literature survey that the research work on the stacking faults in the intercalated compounds of $\mathrm{MoSe}_{2}$ is very poor. Hence, it was decided to work on $\operatorname{In}_{x} \mathrm{MoSe}_{2}(0 \leq x \leq 1)$ and Re-doped $\mathrm{MoSe}_{2}$ viz. $\mathrm{MoRe}_{0.005} \mathrm{Se}_{1.995}, \mathrm{MoRe}_{0.001} \mathrm{Se}_{1.999}$ and $\mathrm{Mo}_{0.995} \mathrm{Re}_{0.005} \mathrm{Se}_{2}$ single crystals [1-10]. Very recently, we have reported intrinsic stacking faults in these materials [9].

\section{Experimental details}

For the X-ray diffraction work, several small crystals from each group were finely ground using an agate mortar and filtered through 106 micron sieve to obtain grains of nearly equal size. X-ray powder patterns were recorded on Philips diffractometer by using Cuk $\alpha$ radiation. The X-ray diffractograms of $\operatorname{In}_{x} \mathrm{MoSe}_{2}$ $(0 \leq x \leq 1)$ and Re-doped $\mathrm{MoSe}_{2}$ viz. $\mathrm{MoRe}_{0.005} \mathrm{Se}_{1.995}$, $\mathrm{MoRe}_{0.001} \mathrm{Se}_{1.999}$ and $\mathrm{Mo}_{0.995} \mathrm{Re}_{0.005} \mathrm{Se}_{2}$ single crystals were adduced in our earlier paper [1-10]. The input parameters taken from the X-ray diffractograms of each crystal were tabulated in Tables 1 and 2, which have been used in present calculation. 
Table 1. Input parameters of $\operatorname{In}_{\mathbf{x}} \mathrm{MoSe}_{2}(0 \leq x \leq 1)$ single crystals.

\begin{tabular}{|c|c|c|c|c|c|c|c|c|c|c|c|c|}
\hline \multirow[b]{2}{*}{$\begin{array}{c}h k l \\
\text { values }\end{array}$} & \multicolumn{3}{|c|}{$\mathrm{In}_{0.25} \mathrm{MoSe}_{2}$} & \multicolumn{3}{|c|}{$\mathrm{In}_{0.50} \mathrm{MoSe}_{2}$} & \multicolumn{3}{|c|}{$\mathrm{In}_{0.75} \mathrm{MoSe}_{2}$} & \multicolumn{3}{|c|}{$\mathrm{InMoSe}_{2}$} \\
\hline & $\begin{array}{c}d- \\
\text { values, } \\
\AA\end{array}$ & $\begin{array}{c}\text { Peak } \\
\text { intensity } \\
\text { counts } \\
\left(\beta_{2 \theta}\right), \\
\mathrm{s}^{-1}\end{array}$ & $\begin{array}{l}\text { Angle } \\
(2 \theta)\end{array}$ & $\begin{array}{c}d- \\
\text { values, } \\
\AA\end{array}$ & $\begin{array}{c}\text { Peak } \\
\text { intensity } \\
\text { counts } \\
\left(\beta_{2 \theta}\right) \\
\mathrm{s}^{-1}\end{array}$ & $\begin{array}{l}\text { Angle } \\
(2 \theta)\end{array}$ & $\begin{array}{c}d- \\
\text { values, } \\
\AA\end{array}$ & $\begin{array}{c}\text { Peak } \\
\text { intensity } \\
\text { counts } \\
\left(\beta_{2 \theta}\right), \\
\mathrm{s}^{-1}\end{array}$ & $\begin{array}{l}\text { Angle } \\
(2 \theta)\end{array}$ & $\begin{array}{c}d- \\
\text { values, } \\
\AA\end{array}$ & $\begin{array}{c}\text { Peak } \\
\text { intensity } \\
\text { counts } \\
\left(\beta_{2 \theta}\right), \\
\mathrm{s}^{-1}\end{array}$ & $\begin{array}{l}\text { Angle } \\
(2 \theta)\end{array}$ \\
\hline 102 & 2.6158 & 0.080 & 34.255 & 2.6111 & 0.140 & 34.315 & 2.6082 & 0.080 & 34.395 & 2.6097 & 0.240 & 34.335 \\
\hline 103 & 2.3774 & 0.060 & 37.810 & 2.3756 & 0.080 & 37.840 & 2.3756 & 0.120 & 37.840 & 2.3774 & 0.080 & 37.810 \\
\hline 105 & 1.9152 & 0.100 & 47.430 & 1.9112 & 0.080 & 47.535 & 1.9147 & 0.080 & 47.445 & 1.9171 & 0.080 & 47.380 \\
\hline
\end{tabular}

Table 2. Input parameters of Re-doped single crystals.

\begin{tabular}{|c|c|c|c|c|c|c|c|c|c|}
\hline \multirow{4}{*}{$h k l$} & \multicolumn{3}{|c|}{$\mathrm{MoRe}_{0.005} \mathrm{Se}_{1.995}$} & \multicolumn{3}{c|}{$\mathrm{MoRe}_{0.001} \mathrm{Se}_{1.999}$} & \multicolumn{3}{c|}{$\mathrm{Mo}_{0.995} \mathrm{Re}_{0.005} \mathrm{Se}_{2}$} \\
\cline { 2 - 11 } values & $\begin{array}{c}\text { Peak } \\
\text { values, } \\
\AA\end{array}$ & $\begin{array}{c}\text { intensity } \\
\text { counts } \\
\left(\beta_{2 \theta}\right) \\
\mathrm{s}^{-1}\end{array}$ & $\begin{array}{c}\text { Angle } \\
(2 \theta)\end{array}$ & $\begin{array}{c}d- \\
\text { values, } \\
\AA\end{array}$ & $\begin{array}{c}\text { Peak } \\
\text { intensity } \\
\text { counts } \\
\left(\beta_{2 \theta}\right), \\
\mathrm{s}^{-1}\end{array}$ & $\begin{array}{c}\text { Angle } \\
(2 \theta)\end{array}$ & $\begin{array}{c}d- \\
\text { values, } \\
\AA\end{array}$ & $\begin{array}{c}\text { insity } \\
\text { counts } \\
\left(\beta_{2 \theta}\right), \\
\mathrm{s}^{-1}\end{array}$ & $\begin{array}{c}\text { Angle } \\
(2 \theta)\end{array}$ \\
\hline 102 & 2.6158 & 0.080 & 34.255 & 2.6111 & 0.140 & 34.315 & 2.6082 & 0.080 & 34.395 \\
\hline 103 & 2.3774 & 0.060 & 37.810 & 2.3756 & 0.080 & 37.840 & 2.3756 & 0.120 & 37.840 \\
\hline 105 & 1.9152 & 0.100 & 47.430 & 1.9112 & 0.080 & 47.535 & 1.9147 & 0.080 & 47.445 \\
\hline
\end{tabular}

The formulae of deformation and growth probabilities, which are given by Warren [11] as follows $B_{2 \theta}=\frac{360 \tan \theta}{\pi^{2}} l\left(\frac{d}{c}\right)^{2}(3 \alpha+3 \beta) \quad$ for $l$ even

and

$B_{2 \theta}=\frac{360 \tan \theta}{\pi^{2}} l\left(\frac{d}{c}\right)^{2}(3 \alpha+\beta) \quad$ for $l$ odd,

where $B_{2 \theta}$ denotes the full width at half the maximum intensity, $d$ is the $h k l$ spacing, $c$ is equal to $2 d_{002}, \alpha$ and $\beta$ are the deformation fault probability and the growth probability, respectively. The presently calculated values of $\alpha$ and $\beta$ are shown in Tables 3 and 4. All the calculations were performed for (102), (103) and (105) reflections.

\section{Results and discussion}

It is seen from Tables 3 and 4 that there is a significant variation in the deformation fault probability $(\alpha)$ and growth probability $(\beta)$ due to off-stoichiometry, i.e. composition of indium in the $\mathrm{MoSe}_{2}$ and Re-doped $\mathrm{MoSe}_{2}$ viz. $\mathrm{MoRe}_{0.005} \mathrm{Se}_{1.995}, \mathrm{MoRe}_{0.001} \mathrm{Se}_{1.999}$ and $\mathrm{Mo}_{0.995} \mathrm{Re}_{0.005} \mathrm{Se}_{2}$ single crystals. This variation of stacking faults, i.e. both probabilities, is caused by creation of defects in the crystal. The values of $\alpha$ and $\beta$ are nearly of the same order. Any theoretical or experimental proof of this type calculation is not available in the literature. Therefore, it is difficult to compare our results with them and write any strong remarks. The calculation of the stacking faults may be considered as one of the guidelines for further detailed study of defects and various properties of crystals.
It was shown by Cockyne et al. [12] that significant improvement in resolution of the structure of lattice defects could be obtained from dark field electron micrographs taken in weakly diffracted beams. Using the weak beam technique, Ray and Cockyne [13] directly observed splitting of dislocations into partials of $\mathrm{Si}$. Since then, several investigators [14-18] and most recently Mao and Knowles [19] have observed dissociation of lattice dislocations into partials. The presence of stacking faults has been recently shown in $\mathrm{WS}_{2}$ single crystals by Agarwal et al. [20]. All these investigators have used the spacing between partials to estimate the stacking fault energy. Gross and Teichler [21] formulated a real space method, Kenway [22] atomic lattice stimulation and Xiliang et al. [23] a method based on the improved embedded-atom method for theoretical estimation of stacking fault energies in different materials. All these estimations where compared with SFE measurements made using weak beam techniques show a favourable agreement.

The low values of stacking fault probabilities allows for easy gliding on the basal plane of $\operatorname{In}_{\mathrm{x}} \mathrm{MoSe}_{2}$ $(0 \leq x \leq 1)$ and Re-doped $\mathrm{MoSe}_{2}$ viz. $\mathrm{MoRe}_{0.005} \mathrm{Se}_{1.995}$, $\mathrm{MoRe}_{0.001} \mathrm{Se}_{1.999}$ and $\mathrm{Mo}_{0.995} \mathrm{Re}_{0.005} \mathrm{Se}_{2}$ layers thus leading to easy creation of stacking faults and their excellent properties as solid lubricating agent [20].

Table 3. Presently calculated values of stacking fault probabilities of $\operatorname{In}_{x} \mathrm{MoSe}_{2}(0 \leq x \leq 1)$ single crystals.

\begin{tabular}{|c|c|c|c|c|}
\hline $\begin{array}{c}\text { Stacking } \\
\text { fault } \\
\text { probability }\end{array}$ & $\mathrm{In}_{0.25} \mathrm{MoSe}_{2}$ & $\mathrm{In}_{0.50} \mathrm{MoSe}_{2}$ & $\mathrm{In}_{0.75} \mathrm{MoSe}_{2}$ & $\mathrm{InMoSe}_{2}$ \\
\hline$\alpha$ & 0.0025037 & 0.0026711 & 0.0023574 & 0.0033694 \\
\hline$\beta$ & 0.0025299 & 0.0027837 & 0.0022524 & 0.0032857 \\
\hline
\end{tabular}




\section{Conclusion}

X-ray diffractogrms have clearly mentioned that the difference in $\operatorname{In}_{x} \mathrm{MoSe}_{2}(0 \leq x \leq 1)$ and Re-doped $\mathrm{MoSe}_{2}$ viz. $\mathrm{MoRe}_{0.005} \mathrm{Se}_{1.995}, \quad \mathrm{MoRe}_{0.001} \mathrm{Se}_{1.999}$ and $\mathrm{Mo}_{0.995} \mathrm{Re}_{0.005} \mathrm{Se}_{2}$ single crystals is caused by their offstoichiometry. The analysis of deformation fault probability $(\alpha)$ and growth probability $(\beta)$ of all the single crystals has shown that indium intercalation and Re-doping affects the stacking fault probabilities. The experimental proof is not available in the literature but, the present investigation provides an important set of data for most of the single crystals, which can be very useful for further comparison either with theory or experiment. This study on the stacking faults in other single crystals is in progress.

\section{References}

1. Aditya M. Vora // Cryst. Res. Tech. 42, p. 286 (2007).

2. A.M. Vora, M. Phil. Dissertation, Sardar Patel University, Vallabh Vidyanagar, India (1998).

3. Mihir M. Vora, and Aditya M. Vora // Cryst. Res. Tech. 41, p. 803 (2006).

4. Mihir M. Vora, and Aditya M. Vora // Cryst. Res. Tech. 42, p. 50 (2007)

5. Mihir M. Vora, and Aditya M. Vora // Cryst. Res. Tech. 42, p. 186 (2007).

6. A.M. Vora, and P.K. Garg // Indian J. Phys. 74A, p. 563 (2000).

7. Mihir M. Vora, and Aditya M. Vora // Chalcogenide Lett. 4, p. 77 (2007).
8. M.M. Vora, and A.M. Vora, Chalcogenide Lett. 4, p. 85 (2007).

9. M.M. Vora, and A.M. Vora // Chalcogenide Lett. 4, p. 97 (2007).

10. Aditya M. Vora // Chalcogenide Lett. 5, p. 17 (2008).

11. B.E. Warren // Progr. Met. Phys. 8, p. 493 (1959).

12. D.J.H. Cockayne, I.L.F. Ray, and M.J. Whelan // Phil. Mag. 20, p. 265 (1969).

13. I.L.F. Ray, and D.J.H. Cockayne // Proc. Roy. Soc. A325, p. 543 (1971).

14. D. Stenkamp, and W. Jager // Phil. Mag. A20, p. 1369 (1992).

15. S. Mckernain, G.J. Zhu, and C.B. Carter // Phil. Mag. Lett. 64, p. 349 (1991).

16. F. Cosandey, and R. Plano // Scr. Metall. Mater. 25, p. 723 (1992).

17. K. Suzuki, M. Ichihara, and S. Takeuchi // Jpn. J. Appl. Phys. 33, p. 1114 (1994).

18. J.K. Yau, P.R. Munroe, and C.C. Sorrell // Physica C 243, p. 359 (1995).

19. Z. Mao, and K.M. Knowles // Phil. Mag. A73, p. 699 (1996).

20. M.K. Agarwal, Y. Patel, and M.N. Vashi // Indian J. Phys. 37, p. 464 (1999).

21. A. Gross, and H. Teichler // Phil. Mag. B64, p. 413 (1991).

22. P.R. Kenway // Phil. Mag. B68, p. 171 (1993).

23. N. Xiliang, R. Wang, Y. Yiying, Z. Yumei, and D. Wang // Solid State Communs. 96, p. 729 (1995). 